\title{
Enhancement of Power Generation in Highway Using Wind Energy Conversion System Integrated with PV
}

\author{
Kiruba.K ${ }^{\mathrm{a}, 1}$, Deepika.D ${ }^{\mathrm{b}}$, Jaitha.G ${ }^{\mathrm{b}}$, Madhuja.S ${ }^{\mathrm{b}}$ \\ a Assistant Professor, SRM TRP Engineering College, Trichy, TN, India \\ ${ }^{\mathrm{b}} U G$ Student, SRM TRP Engineering College, Trichy, TN, India
}

\begin{abstract}
The rising global population and economic growth, combined with rapid urbanization, will result in a significant increase in energy demand. To solve this problem in the coming years, the world will need significantly more resources, primarily cleanly produced electricity. On the other hand, electricity demand is rising at twice the rate of overall energy consumption, and is expected to more than double by 2040. So, in order to meet the energy demands, the proposed approach includes a concept of a new Vertical Axis Wind Turbine (VAWT) design that generates power from moving vehicles and further integrated with PV for increased power generation. Seasonal variations can be accommodated by the related hybrid scheme. Using a charge controller, the produced power can be stabilized to a $12 \mathrm{~V}$ output. The generated energy can be stored in batteries or supplied to the grid, acting as an energy storage device for society. The power that has been stored can be used in the future or during non-windy seasons.
\end{abstract}

Keywords. VAWT, Solar Energy, PV, Charge Controllers

\section{Introduction}

Renewable energy, also known as non-conventional sources, is generated from naturally replenished sources or processes on a consistent way. Wind and solar energy can now be harnessed effortlessly and maintained in more sophisticated and less expensive ways, and renewable energy sources are becoming a more important source of electricity. WECSs are commonly used in distributed generation systems, micro grids, and smart grids today, as well as in stand-alone systems for supplying electricity to isolated loads. Appropriate energy management processes must be used in both of these applications in order to optimize wind turbine energy output and pass windgenerated energy to consumers with high performance. Solar PV systems transform sunlight into electricity using cells. One or two layers of a semi conducting material, typically silicon, make up a PV cell. As light shines on a cell, it generates an electric field that causes electricity to flow through the layers. The movement of energy is proportional to the strength of the sun. PV cells are measured in terms of how much energy they produce. Meanwhile the hybrid power system is entirely reliant on intermittent renewable energy sources; the output voltage fluctuates, causing harm to devices that need a constant supply [1]. Since solar and wind power are intrinsically

\footnotetext{
${ }^{1}$ Kiruba.K, Assistant Professor, SRM TRP Engineering College, Trichy, India;

E-mail:kiruba.k@trp.srmtrichy.edu.in.
} 
intermittent and volatile, increasing their penetration in existing power systems may pose significant technical challenges, especially for poor grids or stand-alone systems lacking adequate storage capacity [2]. The average wind velocity in potential locations, such as coastal areas, is still now below the required level for effective operation of wind turbine [3]. The VAWT is built in such a way that is efficient to catch wind from all directions; with a power output of $28 \mathrm{~W}$ for a speed of $6.1 \mathrm{~m} / \mathrm{s}$; the VAWT's efficiency can be improved by changing the size and shape of the blade; the theoretical and experimental results vary since the theoretical measurement assumes that the wind reaches all eight turbine blades, which is not realistic [4]. This idea of producing a significant amount of energy without burning fossil fuels, which is the largest source of $\mathrm{CO} 2$ emissions, and thereby helps to minimize reliance on fossil fuels and fossil fuel transportation [5].

\section{Objective}

The main aim of designing a wind turbine on a highway incorporated with PV is to contribute to the national trend of energy production in a realistic way. Traditionally, wind turbines have been used in rural areas. To generate electricity, the turbines will use the wind draught generated by vehicles on the highways. By integrating a PV system along with Wind Energy Systems the overall power output of the system can be enhanced.

\section{Proposed Design}

Our proposed model is shown in Figure. 1, has a wind turbine constructed in vertical manner so that it can effectively generate electricity from wind during vehicle movement. These turbines can be erected on highways with a high amount of fastmoving traffic. The produced electricity will be stored in batteries.

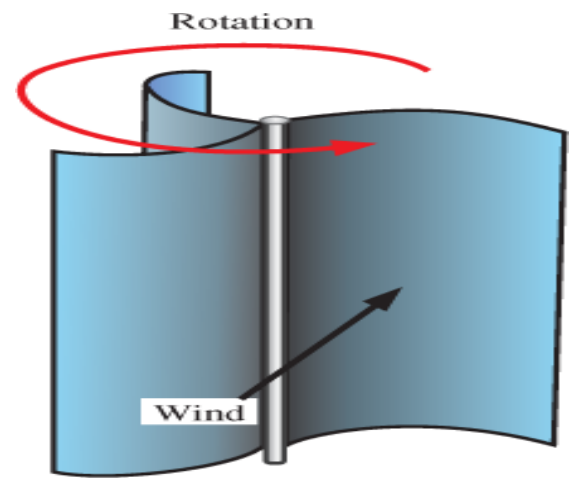

Figure 1. Vertical Axis Wind Turbine

VAWT has slower blade speeds since the blades are closer to the axis of rotation. Hence it is capable of producing electrical energy at very low wind speeds. So in order to improve the output the system design includes a solar PV combined with Wind [6] is shown in Figure. 2 . 


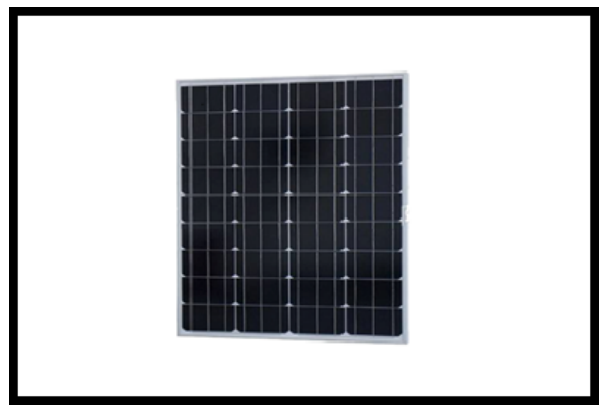

Figure 2. Solar Pane

\section{Design Methodology}

In the Proposed system as shown in Figure. 3, Vertical Axis Wind Turbine (VAWT) integrated with Photovoltaic cell can be installed in highway median strip to produce power during high demand. The wind power obtained from rotation of blades is coupled with permanent magnet DC generator to generate DC output. The output of the designed turbine system is limited to low value since it has slower blade speeds. Hence it is efficient of producing electrical energy at low wind speeds. Hence in order to achieve high output, a PV cell is integrated with Vertical Axis Wind Turbine (VAWT) [7]. In order to prevent the battery from being overcharged, a charge controller can be used to regulate its output. The primary ratings of the charge controller can be of 15$\mathrm{A} / 200-\mathrm{W}$ unit and by the mean way to speed up the process of solar charging the most common and efficient MPPT algorithm is used. The algorithm examines the output power obtained from panel and compares them with battery potential to attain maximum current into the battery. DC-DC converters are commonly used to efficiently generate a regulated voltage from a source that may or may not be well managed to a variable load. A LUO converter is used here, which steps up the voltage to produce a voltage higher than input voltage.

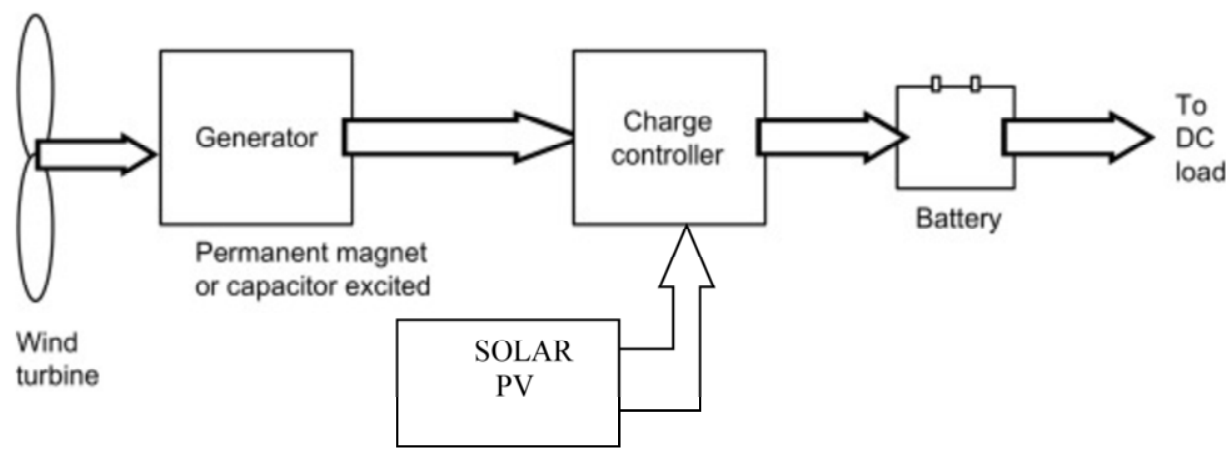

Figure 3. Block diagram of Proposed Methodology 


\section{A) Vertical Axis Wind Turbine:}

The main aim of using VAWT instead of HAWT is the turbines constructed in a vertical manner don't require yaw control mechanism, which is nothing but the rotation of nacelle according to the direction of wind for power generation [6-10]. Hence the vertically constructed turbines are free from detecting wind and alignment mechanisms.

\section{B) Generator}

A permanent magnet DC generator is used here with double winding structure. The generators are mainly used here to extract the output from rotation of wind blades.

\section{C) Solar PV}

The most commonly used renewable source for transforming light energy into electrical energy is Solar. It is attained by using solar cells that exhibits photovoltaic effect. In our proposed methodology single solar cells are combined together to form segments such as panels capable of generating a voltage of 0.5 to 0.6 volts. Thereby for efficient amount of energy production additional number of solar modules can be used. Also the solar panels integrated along with wind turbine in our proposed design also contributes for enhancing the power, since the output generated from wind energy systems is not sufficient.

\section{D) Charge Controller}

The main purpose of using charge controllers is to prevent battery getting damaged from over charging. It is used to regulate the output parameters obtained from solar systems formerly entering into the battery. The process of comparing the output parameters of solar and battery is effectively achieved by using Maximum Power Point Tracking Algorithm. In addition converters can also be used to achieve maximum output.

\section{Results and Discussions}

The proposed system as shown in Figure. 4, is simulated in SIMULINK to obtain a constant voltage of $12 \mathrm{~V}$ from charge controller. The output obtained from solar PV is accelerated by comparing its output with MPPT techniques. As shown in figure. 5, The output ripples are eliminated and the output voltage is effectively increased by using a LUO converter, which is a form of buck boost converter. The hardware model is realized as shown in Figure. 6. 


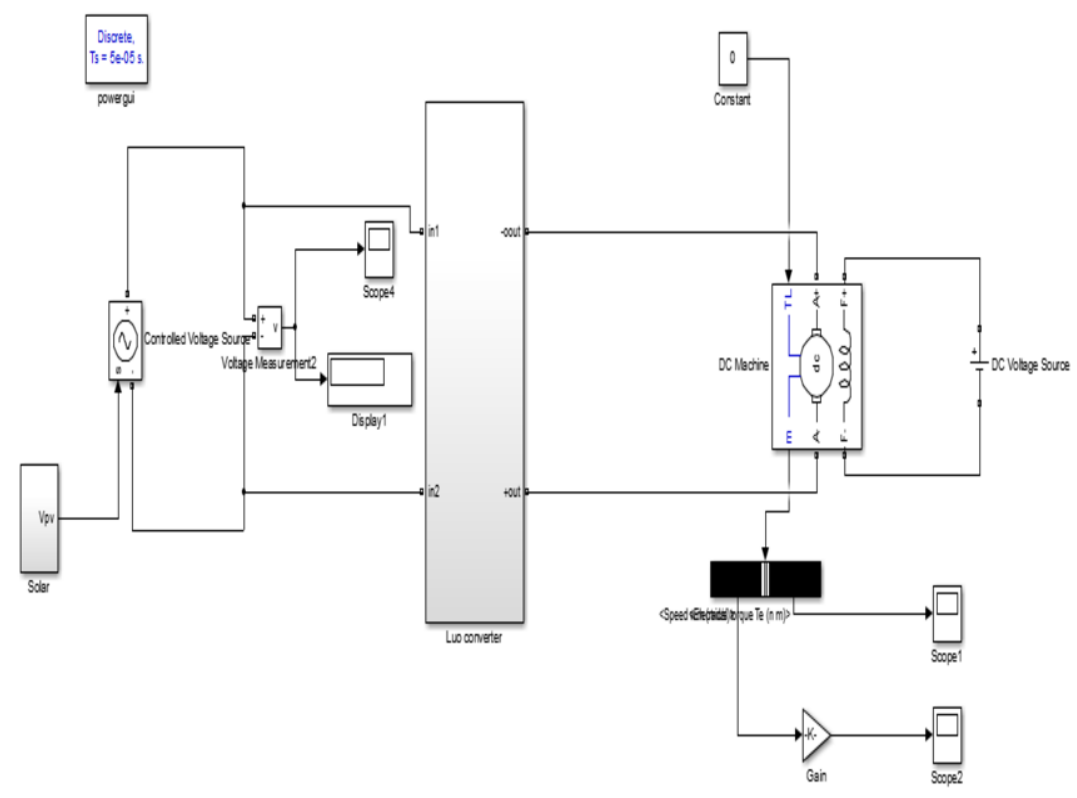

Figure 4. Simulink model of proposed system

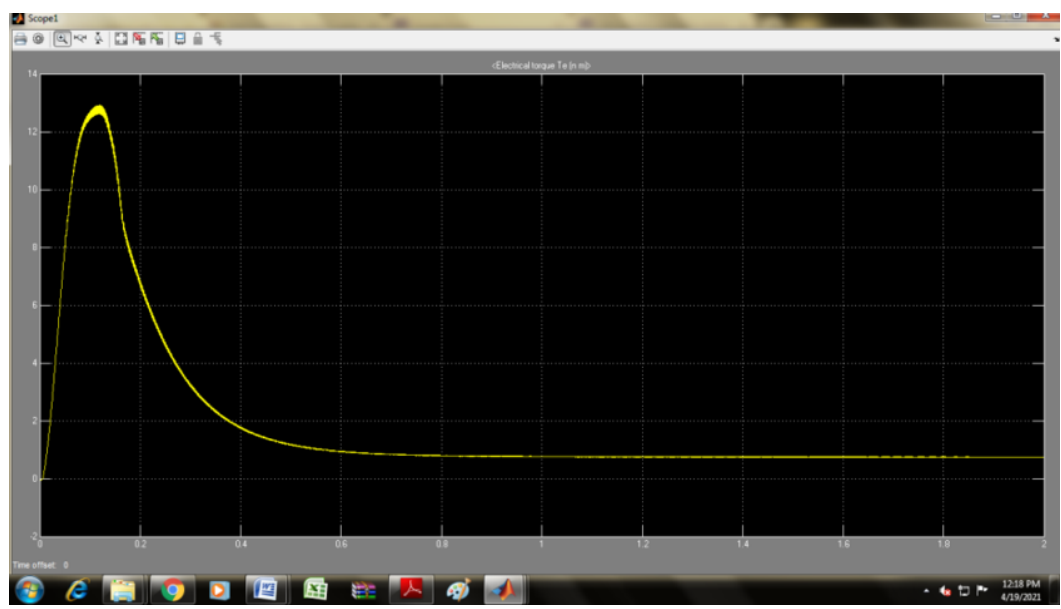

Figure 5. Simulation output for charge controller 


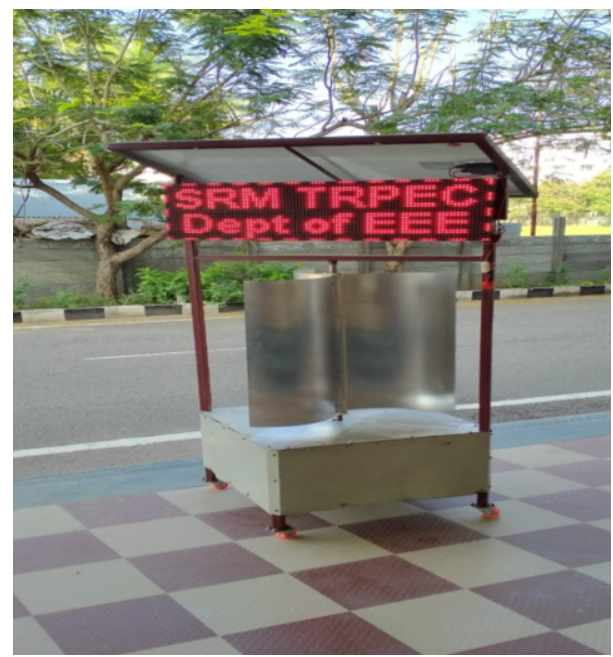

Figure 6. Hardware model of proposed system

\section{Conclusion}

On highways, the proposed vertical axis wind mill model integrated with solar PV will be a good source of renewable energy. Wind energy produced by moving vehicles on highways can be used to produce electrical energy, and further it can be enhanced by combining this output with PV output. The obtained output can be stored in a battery and used for street lighting, traffic signals, and road studs, among other things. This design philosophy is intended to be environmentally friendly and long-lasting. If these turbines can be mounted on long, high-speed transmission lines, it is possible to produce a significant amount of electrical energy, which can be used in a variety of ways that resolve the energy crisis.

\section{References}

[1] Mohod, S. B., Parihar, V. R., \& Nimkar, S. D. (2018). Hybrid power system with integration of wind, battery and solar PV system. In IEEE International Conference on Power, Control, Signals and Instrumentation Engineering, ICPCSI 2017 (pp. 2332-2337). Institute of Electrical and Electronics Engineers Inc. https://doi.org/10.1109/ICPCSI.2017.8392134

[2] Badwawi, R. A., Abusara, M., \& Mallick, T. (2015). A Review of Hybrid Solar PV and Wind Energy System. Smart Science, 3(3), 127-138. https://doi.org/10.1080/23080477.2015.11665647

[3] Ehsan, M. M., Ovy, E. G., Chowdhury, H. A., \& Ferdous, S. M. (2012). A Proposal of implementation of ducted wind turbine integrated with solar system for reliable power generation in Bangladesh. International Journal of Renewable Energy Research, 2(3), 397-403. https://doi.org/10.20508/ ijrer.36008

[4] Kulkarni, S., Kulkarni, S. A., \& Birajdar, M. R. (2016). Vertical Axis Wind Turbine for Highway Application. Imperial Journal of Interdisciplinary Research (IJIR), 2(10), 1-5.

[5] Sharma, P., \& Harinarayana, I. (2013). Solar energy generation potential along national highways. International Journal of Energy and Environmental Engineering, 4(1), 1-13. https://doi.org/10.1186/ 2251-6832-4-16

[6] Bhati, V.S., Berwal, R., \& Kasniya, B. (2018). Modelling of Hybrid Solar / Wind Energy System for Rural, Remote and Hilly Areas in Rajasthan ( India ). 
[7] Brijeshkumar N. Trivedi and Prof. Piyush Patel "Simulation and Analysis of Wind-Solar Hybrid Energy Conversation System", International Journal for Technological Research in Engineering ISSN (Online): 2347 - 4718 (February - 2018).

[8] Hybrid power generation system using wind energy and solar energy. (2016). International Journal of Advance Engineering and Research Development, 3(07). https://doi.org/10.21090/ijaerd.030719

[9] N. Venkata Subbaiah and S.Deva Kumar "Power generation by using highway vertical axis wind mill", 2017 IJCRT, Volume 5, Issue 4, December 2017.

[10] Hannoon, N., Vijayakumar, V., Vengatesan, K., \& Hidayat, N. (2019). Stability Assessment on Doubly Fed Induction Generator (DFIG) Wind Turbine Micro Grid Power System. Journal of Computational and Theoretical Nanoscience, 16(2), 778-785.

[11] Kumar, A., \& Singh, S. K. (2015). Wind Power Generation On Highway. IJIRST-International Journal for Innovative Research in Science \& Technology|, 1(12), 426-431. Retrieved from www.ijirst.org 